\title{
Um foco de energia: o Collège de Sociologie e a noção de sagrado (1937-1939)
}

JÚLIA VILAÇA GOYATÁ

Em nota pública do Collège de Sociologie de 7 de outubro de 1938 assinada por seus fundadores, Georges Bataille (1897-1962), Roger Caillois (1913-1987) e Michel Leiris (1901-1991), lê-se:

O Collège de Sociologie foi definido essencialmente como sendo um organismo de pesquisas e estudo, e continua o sendo. Mas em sua fundação ele estava reservado à eventualidade de ser outra coisa se pudesse: um foco de energia. Os eventos de ontem sugerem, talvez ordenem, que coloquemos um acento sobre esse aspecto de nosso empreendimento. É por esse motivo que o Collège toma a iniciativa dessa declaração pública (1995a: 362, grifos meus)ํ.

A declaração, publicada na Nouvelle Revue Française (N.R.F.) logo após a assinatura do acordo de Munique, deixa claro o ponto que quero aqui explorar: o sentido político da empreitada proposta pelo Collège de Sociologie, grupo fundado e animado por Bataille, Caillois e Leiris na França, nos anos que antecederam a Segunda Guerra Mundial (1937-1939) ${ }^{2}$. Se é certo que o fenômeno Collège não pode ser separado de outras tentativas de oposição à ascensão nazi-fascista que sacudiram a Europa do entreguerras, também é verdade que a construção de sua postura política se deu de maneira peculiar. A pergunta a se fazer é justamente essa: qual era a especificidade desse grupo diante de tantas outras experiências? O que significa ser "um foco de energia" nos termos colocados pelos autores? Veremos como a noção de sagrado, proclamada como tema central de debate do grupo, se torna fundamental nesse sentido: é a partir dela que o Collège mostrará seu feitio a um só tempo investigativo e político.

1 Esta e as próximas traduções presentes no texto são de minha autoria.

2 O acordo de Munique, assinado em setembro de 1938, cujo objetivo era discutir a situação da Checoslováquia, culminou com a conquista alemã de parte da região, os Sudetas. Embora ficasse acordado que esta seria a última reivindicação territorial de Adolf Hitler (1889-1945), um ano depois o governante invadiria o resto da Checoslováquia iniciando a Segunda Guerra Mundial. O acordo de Munique dava a ver, assim, de maneira explícita, a crise internacional instalada desde a ascensão de Hitler ao poder em 1933. 
Tomado muitas vezes, conforme comenta Jean Jamin (1980), como uma experiência "amadora” ou um "desvio" malsucedido do movimento surrealista, o Collège parece oferecer à reflexão um bom exemplo de aventura intelectual, em seu melhor sentido (1980:13). Quase nunca recuperados pela antropologia em geral e pela brasileira em particular, tanto a experiência do Collège quanto os trabalhos de seus autores fundadores, parecem trazer à cena uma questão fundamental e contemporânea: a dos meios possíveis de aproximação entre os campos da religião e da política. Consolidadas áreas de estudo da teoria antropológica essas dimensões da vida social são comumente tomadas de forma separada; trata-se aqui de tentar tornar visível uma das formas de seu contato ${ }^{3}$.

\section{Entre a arte e a política, a sociologia}

Não se pode ter uma compreensão precisa do que foi a experiência do Collège de Sociologie sem levar em consideração a participação de seus fundadores em uma profusão de associações artísticas e políticas que o precederam e o circundaram na Paris do entreguerras. Sabe-se que este foi um momento especialmente importante de irrupção de diversas agremiações, tanto artísticas; foi a partir dos anos 1920 que se desenvolveram as vanguardas (como o futurismo, o cubismo, o dadaísmo e o surrealismo), quanto políticas, como era o caso de grupos de inspiração marxista como o Cercle Communiste Démocratique (1932) e a associação Contre-Attaque (1935). Pendendo ora mais para o campo da arte e hora mais para o campo da ação política, embora essas fronteiras fossem opacas naquele momento, esses grupos de intelectuais e artistas, tentavam, cada qual a seu modo, construir uma crítica autêntica da modernidade ocidental. Tratava-se, depois da guerra e, mais tarde, com a ascensão dos regimes nazifascistas, de repensar as convicções iluministas, tentando entender também o porquê da ampliação dos autoritarismos recentes ${ }^{4}$.

\footnotetext{
3 O livro de Dennis Hollier intitulado Le Collège de Sociologie (1995), compilação comentada das conferências do grupo, bem como a grande maioria dos trabalhos de Bataille, Leiris e Caillois não foram, por exemplo, traduzidos para o português. Para trabalhos sobre os autores realizados no campo da antropologia brasileira, ver: Peixoto (2006, 2007, 2011); Motta (2006); Sobral (2008); Goyatá (2016) e De Zorzi (2013). Segundo Jean Jamin, a experiência do Collège tampouco foi recuperada em estudos franceses, sendo o trabalho de Hollier, feito desde os Estados Unidos, o mais significativo nesse sentido (1980: 13).

4 Muito foi escrito sobre o ambiente intelectual da França nesse momento e não se trata aqui de fazer uma consideração histórico-sociológica sobre ele. A descrição de Maurice Nadeau do surrealismo (1985) contempla não só o movimento, mas também a temperatura da época em que foi gestado. As biografias de Georges Bataille (Surya, 1992) e de Michel Leiris (Armel, 1997), bem como entrevistas dadas por Caillois (1981a) e Leiris (1968 e 1992b), também estão atentas ao contexto do entreguerras francês. Em minha dissertação de mestrado (2012), faço uma descrição mais detida sobre as experiências artísticopolíticas desse momento, principalmente aquelas nas quais estiveram envolvidos Georges Bataille e Michel Leiris. Alguns exemplos delas são as revistas Documents (1929), Minotaure (1933) e La Bête Noire (1936), bem como os grupos Contre-Attaque (1935), Cercle Communiste Démocratique (1932) e Acéphale (1936).
} 
Ainda que essas experiências tivessem um objetivo crítico comum, sua forma era bastante variada e, mais que isso, a questão da forma em si mesma era um problema central para esses grupos. A pergunta que se faziam era: qual o melhor modelo de construção do ativismo político e da crítica à modernidade? Alguns apostavam em um modelo artístico, entendido como mais indireto, enquanto outros se arriscavam através de um modelo político, concebido como mais direto. Vejamos um trecho do diário íntimo de Leiris, de dezembro de 1935, em que o autor aponta justamente para esse debate:

Contra a tendência (ou melhor: as pretensões) totalitárias do surrealismo: o artista não tem que, a qualquer custo, se misturar a todos os problemas da ordem do dia (...); ele também não deve visar a arte pura, se fechar na torre de marfim, ficar preso numa jaula; simplesmente, ele se coloca diante de todos os problemas da ordem do dia mas os resolve à sua maneira, segundo seus próprios meios. Limitar as devastações da arte mantendo-a dentro de seus limites. Fracasso prático de Dada que, ao suprimir essas barreiras, só conseguiu chegar à pior confusão: a mistura do estetismo a tudo. É plenamente compreensível que Satie tenha sido ao mesmo tempo um grande músico e um bom militante comunista; mas essas duas coisas permaneciam para ele distintas: ele não fazia música enquanto comunista nem comunismo enquanto músico. Restituir à arte seu caráter de jogo, - não de jogo gratuito, mas de jogo na qual tudo o que é humano se encontra implicado. Contra o atual ponto de vista repreendo Bataille de se ocupar da política, alegando que, com isso, ele perde seu tempo, que se desvia de seu dom poético; não restam dúvidas que Le Bleu du ciel é um livro admirável, superior literariamente à produção daqueles que, como eu, se reivindicam somente como literatos" (Leiris 2004:294).

Aqui Leiris faz uma crítica direta ao surrealismo, grupo da qual fez parte de 1924 a 1929, quase dez anos antes de sua entrada no Collège de Sociologie 5 . A apreciação crítica incide justamente sobre o fato do movimento ter tomado uma forma não artística, isto é, ter cedido a uma forma política enrijecida pelas exigências partidárias. A posição do autor é, assim, a de defesa da arte enquanto modelo específico: embora seu conteúdo possa ser político, seu contorno de atuação deve ser próprio; ela, portanto, não deveria estar submetida à política. Para outros, como para Bataille no contexto de atuação no grupo Contre-Attaque, por exemplo, a posição era contrária: a arte já não conseguia sustentar em sua forma a força política necessária ao momento, tratava-se de extrapolar seus limites; como ele mes-

5 Leiris chega ao movimento através do artista plástico André Masson (1896-1987), com quem manteve contato a partir de 1922, participando do conhecido grupo de artistas e intelectuais da rua Blomet, um dos braços do surrealismo nascente. Ele rompe com André Breton (1896-1966) em 1929, quando o movimento se vincula diretamente ao Partido Comunista Francês, o PCF. Escritor e poeta Leiris se inicia na antropologia nos anos 1930, quando é convidadado por Marcel Griaule para participar de uma missão francesa em terras africanas: a missão Dacar-Djibouti (1931-1933). A partir dessa viagem ele fará sua formação na disciplina na École Pratique de Hautes Études ocupando a partir de 1934 um cargo oficial no Musée d'Etnographie du Trocadéro, responsável pelo departamento de África negra da instituição. Para mais detalhes sobre a trajetória de Leiris ver: Leiris (1968, 1992b); Armel (1997) e Brumana (2005). 
mo diz em carta a Leiris era preciso tentar "ver se é possível ajudar as pessoas a tomarem consciência daquilo que elas vivem e as impedir (...) de preferirem fazer papel de marionetes” (Bataille 2004:117) .

Assim, é a problematização, e mais que ela, a experimentação dos modelos de atuação política que parece estar no centro do debate entre os fundadores do Collège nos anos que precedem a sua fundação. A oscilação entre os campos da arte e da política acompanha o nascimento de grande parte das associações desse momento e não seria diferente com o Collège: ele é mais uma resposta a esse debate, mais uma das experiências a serem testadas nesse grande laboratório de pesquisas sobre a atividade política que foi o entreguerras francês. Contudo, o caminho de atuação testado pelo Collège tentaria ultrapassar os conflitos entre a forma arte e a forma politica, privilegiando uma nova dimensão como modelo: a ciência. Mais precisamente, a sociologia, que supostamente forneceria os instrumentos necessários à empreitada. A escolha se dava não apenas porque seus fundadores advinham do campo das humanidades, mas principalmente porque eles acreditavam que na própria estrutura da sociologia havia um elemento ambíguo que interessava destacar.

Desde o nome, Collège de Sociologie, dado por Jules Monnerot (1909-1995), já está colocada a importância do termo "sociologia" para a associação que nascia ${ }^{7}$. É Dennis Hollier (1995), organizador da compilação que reúne as conferencias e textos propositivos do Collège, quem chama a atenção para a importância do invólucro científico que a palavra sociologie dava ao grupo em oposição às outras associações formadas na época. Acéphale (1936-1939), por exemplo, concebida por Georges Bataille junto à André Masson, tivera atuação paralela à do Collège e fora muitas vezes confundida com ele por conta da participação de Bataille em ambos os projetos ${ }^{8}$. Contudo, o caráter deliberadamente anti-intelectualista e ritualístico de Acéphale contrastava com a proposta da associação formada por Bataille com Caillois e Leiris, que se queria mais "cerebral" e menos "visceral" se comparada à primeira (Caillois, 1974: 58). Ao que tudo indica, como vimos acima através do trecho de Leiris, a presença dos amigos balancearia de alguma forma o ímpeto de Bataille, que era quem estava mais próximo de uma postura

6 Funcionário da Bibliothèque Nationale e formado pela renomada École des Chartes (1922) Bataille se envolvera em diversas associações ao longo dos anos 1930. Ao contrário dos amigos Leiris e Caillois ele nunca fizera parte diretamente do movimento surrealista, apesar de frequentar os mesmos círculos de seus participantes. Pelo contrário, Bataille seria identificado por sua veemente oposição à André Breton (ver o panfleto Un cadávre, desenvolvido por ele junto a alguns ex-surrealistas, dentre eles Leiris, em 1930) (Surya 1992; Bataille 2004). Nos anos 1920 e 1930 o autor ficaria também conhecido nas rodas intelectuais parisienses por seus excessos, dentre eles "abuso de álcool, noites em claro, casos amorosos rápidos e frequentação excessiva de bordéis" (Yvert 2004: 107). O grupo Contre-Attaque, "União de Luta dos Intelectuais Revolucionários", foi formado em 1935 com o militante comunista Pierre Kaan (1903-1945) e o historiador Jean Dautry (1910-1968). Nesse momento o recrudescimento da postura política de Bataille se faz visível e certamente se relaciona com a ascensão fascista (Surya 1992).

7 O sociólogo martiniquense Jules Monnerot chega ao Collège por meio de Roger Caillois, de quem era grande amigo nessa época. Os dois se conheceram e se tornaram amigos no âmbito do movimento surrealista de Breton, na qual ingressaram em 1932. Desenvolveram juntos em 1936 a revista Inquisitions que teria apenas um número, precedendo a fundação do Collège de Sociologie.

8 Acéphale seria o projeto mais ousado de Bataille dentre os vários nas quais esteve envolvido nesse período. A sociedade secreta seguida de uma revista homônima, concebida por Bataille e Masson, buscava ser um espaço de reflexão e de ação. Acreditava-se que seria através do planejamento de uma "conjuração sagrada", da destruição e do consumo exacerbado, que se chegaria a uma verdadeira revolução social (Bataille 1970c). Até a execução de um sacrifício humano consentido fazia parte dos planos do grupo, que duraria quatro anos. O primeiro número da revista, anual, sai em junho de 1936 e o último em junho de 1939 (Caillois 1974; Surya 1992). 
política mais radical nos anos $1930^{9}$. É o próprio quem declara, ao fim de sua primeira conferência no Collège, em novembro de 1937, que "o debate aberto hoje deve ter por objeto o conhecimento e não a prática", afirmação, que, como veremos depois, não condiz totalmente com as propostas do grupo, que, pelo menos a princípio, se queria também lócus de ação (Bataille, 1995a: 54).

$\mathrm{Na}$ "Déclaration sur la fondation d'un Collège de Sociologie" redigida por Roger Caillois, texto que apresentava os propósitos do grupo nascente, a sociologia já se colocava em primeiro plano ${ }^{10}$. Além de salientar que o objetivo da associação era estudar as "estruturas sociais" das sociedades modernas, procurando conhecer seus "elementos vitais", Caillois chama a atenção para o fato de que o próprio grupo se constituía enquanto uma "comunidade moral" (Caillois et alii 1995: 26-27). Tratava-se, sem dúvida, de se aproximar das discussões feitas pelo campo da sociologia acadêmica, principalmente através das figuras de Émile Durkheim (1858-1917) e Marcel Mauss (1872-1950). Os próprios termos usados por Caillois na declaração deixam ver a herança conceitual advinda desses autores. A própria ideia de "comunidade moral" é tributária de Durkheim, para quem a sociedade estava concebida em termos de uma aliança moral entre seus membros ${ }^{11}$.

Contudo, ao mesmo tempo que filiada à sociologia acadêmica, a proposição do Collège ultrapassava e confrontava os estudos tradicionais exercidos na universidade, afinal de contas seus fundadores e participantes se propunham a ser a um só tempo "voyeurs" e "cobaias" da "experimentação sociológica", como comenta Jamin (1980: 12). É sobre essa possibilidade simultânea de entender, mas também de viver as experiências coletivas, que Caillois fala quando conclama a formação de uma "comunidade moral" de "caráter virulento" (1995: 27). O próprio termo Collège, de acordo com Monnerot, insinuaria o interesse do grupo em ser mais que uma junção artificial de pessoas, tratava-se de ressaltar as afinidades eletivas entres seus membros.

Desse modo, a novidade do Collège com relação aos grupos propriamente políticos e artísticos que ganhavam solo em Paris no momento em que surgiu era o que Hollier chamou de seu "ativismo epistemológico", que colocava em causa "a separação escolar do conhecimento e da ação" (1995: 21). Tratava-se de uma tentativa de unir reflexão e ação política através do modelo fornecido pela sociologia, essa "ciência de objeto interno", em que "aquele que sabe faz parte do objeto que estuda" (ibidem). Assim, o modelo sociológico é interessante para o Collège pois apresenta-se como um modelo de engajamento: não é possível para um pesquisador da sociedade transcendê-la, olhá-la de fora tal qual um biólogo vê um organismo pelo microscópio. O cientista que observa a vida social está ao mesmo tempo

9 Bataille e Leiris se conheceram em 1924 através de um amigo em comum, Jacques Lavaud (1894-1975). A partir desse momento se tornaram grandes amigos e parceiros de trabalho, apesar se suas divergências em termos de personalidade e atuação política. Já Caillois se torna amigo de Bataille em 1936, quando frequentam juntos o seminário de Alexandre Kojève (1902-1968) sobre Hegel. Leiris e Caillois se conheceram através de Bataille nos anos que antecederam a formação do Collége de Sociologie (Hollier 1995; Surya 1992; Armel 1997; Felgine 2008).

10 A declaração foi publicada no número 3-4 da revista Acéphale em julho de 1937 e contou com as assinaturas de Georges Ambrosino, Georges Bataille, o próprio Roger Caillois, Pierre Klossowski, Pierre Libra e Jules Monnerot. É importante destacar que Leiris, um dos fundadores da associação, não assina o texto. Tudo indica que o fato se relaciona à nota estar publicada em Acéphale, revista com a qual o antropólogo não queria correr o risco de estar identificado naquele momento. Sabe-se que Leiris era extremamente crítico à atuação da sociedade secreta criada por seus amigos, tendo recusado o convite de Bataille para participar da mesma (Armel 1997). Para mais detalhes ver a correspondência entre Bataille e Leiris (2004).

11 Sobre o conceito de sociedade como comunidade moral em Durkheim ver: Les formes élémentaires de la vie religieuse (1968). Sabe-se que Bataille, Caillois e Leiris eram leitores assíduos de Marcel Mauss, sendo que os dois últimos foram também seus alunos. 
experimentando-a e é justamente essa imagem da dupla articulação observador/participante que o Collège de Sociologie queria enfatizar ${ }^{12}$.

A forma concreta de funcionamento das atividades práticas do Collège também não deixava de ser ambígua, estando entre o modelo universitário e o das sociedades secretas como Acéphale: apesar de se assemelhar a um grupo de estudos e dos encontros serem espécies de seminários, sua sede ficava em um lugar pouco provável, os fundos de uma livraria no número 15 da rua Guy Lussac em Paris. Palestras eram dadas semanalmente tanto por seus fundadores quanto por outros participantes e as sessões se davam comumente aos sábados às $9 \mathrm{~h} 30$ da noite, com o custo (por ouvinte) de cinco francos por mês de conferências ${ }^{13}$. A presença de nomes da comunidade intelectual internacional nos encontros ajudava a compor a paisagem por vezes anedótica pela qual foi descrito o grupo: sabe-se que pelo menos Walter Benjamin (1892-1940) e Victória Ocampo (1890-1979) assistiram a algumas sessões ${ }^{14}$.

Se as atividades do Collège eram ortodoxas e similares a cursos universitários, afastando-se de práticas rituais como propusera Acéphale, os temas de suas reflexões, por outro lado, eram ousados e se assemelhavam àqueles do outro grupo batailleano. Ancorado no problema de como realizar uma "conjuração sagrada”, isto é, uma revolução através das forças em jogo nos rituais religiosos, Acéphale de fato prefigurava a centralidade que noção de sagrado teria pouco tempo depois no Collège (Bataille 1970c). Se, como vimos, a sociologia fora a ciência escolhida pelo grupo, não era de qualquer sociologia que se tratava. Como anunciaria Caillois no parágrafo final da declaração de fundação do grupo:

O objeto preciso de nossa atividade visa poder receber o nome de sociologia sagrada, na medida em que esta implica o estudo da existência social em todas as suas manifestações nas quais há a presença ativa do sagrado (1995: 27, grifos meus).

É preciso compreender o lugar que a noção de sagrado ocupa nessa experiência e em que sentido a expressão "sociologia sagrada" é usada pelo grupo.

12 Não cabe aqui um aprofundamento sobre o tema, mas vale dizer que as relações entre a sociologia universitária e a militância política são extensas na França da primeira metade do século XX, sendo que os próprios Durkheim e Mauss fizeram parte de grupos políticos de esquerda, como mostram suas biografias (Fournier 1994; 2007). Também as relações entre o socialismo e o marxismo e a sociologia francesa devem ser mencionadas como elemento importante das relações íntimas entre a ciência e a política nesse momento (Prochasson 1981; Gouarné 2013). Para mais detalhes sobre a sociologia durkheimiana, a universidade e a política francesas. Ver também Heilbron 1985.

13 Em seu primeiro ciclo de atividades, que contempla os anos de 1937 e 1938, por exemplo, os oradores do Collège foram seus diretores (com exceção de Alexandre Kojève, que deu uma conferência), sendo que Leiris tomou a palavra apenas uma vez e Caillois, por motivo de doença, teve que se afastar por muitas semanas deixando Bataille como seu representante. Em seu segundo e terceiros ciclos, de meados de 1938 a meados de 1939, podemos ver sessões mais ecléticas coordenadas por nomes como Pierre Klossowski, Denis de Rougemont, René M. Guastalla, Anatole Lewitzky, Hans Mayer, Georges Duhuit, Jean Paulhan e Jean Wahl, o que demonstrava um interesse maior pelo projeto por parte da intelectualidade parisiense (Hollier 1995).

14 É conhecida a história de que Bataille tinha por hábito hospedar o filósofo Walter Benjamin em sua casa na França e que, por volta de 1940, na iminência da invasão de Paris pelas tropas alemãs, Benjamin o confiou vários de seus escritos, mantidos por ele na Biblioteca Nacional (Surya 1992). Também sabe-se do romance que Caillois mantivera com a editora da revista literária S.U.R., a argentina Victória Ocampo, a partir de 1938 quando a conhecera nas sessões do Collège (Caillois \& Ocampo 1997). 


\section{O sagrado como motor}

Em carta a Bataille de julho 1939 Leiris deixa ver as discordâncias que levariam ao fim as atividades do Collège de Sociologie naquele mesmo ano, à beira da eclosão da Segunda Guerra Mundial:

Trabalhando para redigir o informe das atividades do Collège de Sociologie desde sua fundação em março de 1937 (...) me vi obrigado a refletir mais cuidadosamente, coisa que não havia feito até o presente, sobre o que foi a atividade do Collège nesses últimos anos, e tomei um ponto de vista tão crítico que não me considero verdadeiramente qualificado para me apresentar amanhã como porta-voz de nossa organização. (...) Está indicado que o Collège tem por objetivo o estudo das 'estruturas sociais'. Ora, estimo que faltas graves contra o método estabelecido por Durkheim tenham sido muitas vezes cometidas: trabalho a partir de noções vagas e mal definidas, comparações entre fatos tomados de sociedades com estruturas profundamente diferentes, etc. (...) Ainda que eu não despreze de maneira nenhuma a importância do sagrado nos fenômenos sociais, estimo que sublinhá-la a este ponto - quase tornando o sagrado um princípio único de explicação - está em contradição com as aquisições da sociologia moderna e, notadamente, com a noção maussiana de 'fenômeno total' (Leiris 2004: 121-123).

$\mathrm{Na}$ carta o autor explicita seu incômodo com o lugar intermediário e ambíguo que o Collège ocupava diante da sociologia acadêmica, como descrito acima. Segundo Leiris, a associação não teria se transformado nem em um grupo de estudos rigoroso, que teria como centro a sociologia formulada por Durkheim, e nem uma "comunidade moral”, “ordem” ou "igreja”, tão diferente assim das "habituais associações intelectuais" (idem: 123). De seu ponto de vista, o Collège tinha uma proposta interessante, que era a de trabalhar com os instrumentos teóricos da sociologia, porém não a levava adiante de maneira responsável, na medida em que usava noções chave dessa disciplina de maneira imprecisa e por vezes deformada. A noção de sagrado, ainda de acordo com ele, teria sido sobrevalorizada pelo grupo, ganhando uma centralidade excessiva na explicação dos fenômenos sociais ${ }^{15}$.

A crítica de Leiris confirma, assim, o lugar de destaque que a noção de sagrado teve durante os dois anos de atividade do Collège, apesar de não explicitar em que sentido o conceito havia sido mobilizado pelo grupo. $\mathrm{O}$ que exatamente fazia o autor crer que o sagrado havia sido esgotado, por assim dizer, pelo Collège? E o que significava para eles a realização de uma sociologia sagrada?

Em resposta à carta do colega, naquela que foi a última sessão do Collège de Sociologie, a mesma que Leiris diz não se sentir apto a participar, Bataille esboça um ponto importante para a compreensão

15 Aliette Armel, biógrafa de Leiris, fará sobre esse ponto uma observação interessante: o autor ocupa no Collège de Sociologie uma posição que é oposta à construção de sua imagem no âmbito acadêmico. No início de sua carreira na antropologia, e principalmente a partir da publicação de seu diário africano, L'Afrique Fantôme (1935), Leiris passa a ser considerado literato e pouco científico no ambiente universitário. Já no espaço do Collège, que supostamente teria uma atmosfera mais liberal, ele é aquele que reivindica a cientificidade. Nas palavras de Armel: "ele escreve um texto literário sobre o sagrado num ambiente muito técnico e científico para tal, enquanto ao inverso, sua situação social o coloca para velar ao rigor científico das atividades do Collège” (1997: 388). 
do uso do sagrado pelo grupo ${ }^{16}$. Usando uma metáfora do campo da física, o autor dirá, em nome de todo o grupo, que o sagrado é como uma descarga de forças acumuladas que se produz "em benefício da potência social", sendo que o sacrifício, presente na festa e também na guerra, é um momento privilegiado de sua presença (Bataille 1995b: 809) ${ }^{17}$. Embora a noção tenha para Bataille derivações próprias, que dizem respeito a seu interesse particular pelo misticismo, pela filosofia nietzschiana e pela psicanálise, não parece exagerado estender para o Collège a formulação do sagrado elaborada nesse momento por ele: o sagrado é, antes de tudo, uma força, isto é, um motor de ação política. Seria através das experiências sociais causadas pelo contato com essa força que o Collège acreditava poder encontrar o impulso para a transformação social.

Assim, desde os princípios de fundação da associação estava colocado que era preciso investigar "os pontos de coincidência entre as tendências obsessivas da psicologia individual e as estruturas diretrizes que presidem a organização social e comandam as revoluções” (Caillois et alli 1995: 27). A noção de sagrado era, assim, tomada de empréstimo da sociologia durkheimiana, mas era ao mesmo tempo usada de forma bastante particular. Como bem observara a crítica metodológica de Leiris, havia um uso hiperbólico do sagrado aqui. Além disso, eram as forças disjuntivas do sagrado, capazes de estabelecer revoluções, que interessavam ao Collège. Pode-se pensar, inclusive, que o Collège executava uma espécie torção no conceito durkheimiano, visando torná-lo não só descritivo/explicativo da sociedade, mas também ativo com relação a ela.

Desse modo, em referência à característica ambígua do sagrado descrita por Durkheim, o Collège priorizará uma de duas faces mais que a outra. Se a noção estava definida pelo sociólogo como a qualidade de tudo aquilo que é excepcional à vida cotidiana, portanto, tanto as coisas puras e santas quanto as impuras e sacrílegas; o grupo tomará como matéria de interesse mais o segundo polo da noção que o primeiro. Seriam temas como as guerras, as festas, as sociedades secretas, a sexualidade e o jogo aqueles explorados nas conferências do Collège e era o caráter de proibição, de excesso e de transgressão à norma dessas experiências o que interessava ao grupo compreender e, por vezes, vivenciar ${ }^{18}$. Assim como na concepção durkheimiana, o sagrado era entendido como capaz de gerar exaltação e comoção - a conhecida efervescência coletiva -, elementos que segundo o Collège deviam ser explorados e direcionados

\footnotetext{
16 De fato, a sessão do dia 4 de julho de 1939, que estaria dedicada a um balanço das atividades do grupo, marcaria o fim oficial do Collège, que apesar de algumas pequenas reuniões privadas, não persistiria no ano seguinte, com o começo da guerra. É possível afirmar que a discordância de Leiris quanto aos métodos do grupo foi a fagulha inicial para sua dispersão, atingindo também Caillois e Bataille, que divergiam teoricamente. Para mais detalhes sobre as diferenças entre os autores ver as cartas de Bataille enviadas a Caillois em 1939 e a troca de correspondência entre Bataille e Leiris no período (Bataille 1997; Leiris \& Bataille 2004). Não tive acesso às cartas de Caillois para Bataille, ao que tudo indica, elas não foram publicadas. Hollier, na compilação das missivas enviadas no âmbito do Collège de Sociologie, também afirma não as ter encontrado (1995: 813).

17 Ver o ensaio de Mauss \& Hubert (2005) sobre o sacrifício, certamente uma leitura comum aos membros do Collège.

18 Para ver a compilação de todas as conferências e temas abordados pelo Collège consultar Hollier (1995), fonte fundamental deste trabalho.
} 
para uma ação política subversiva. Tratava-se de pensá-los como forças motrizes para a destruição da ordem estabelecida $^{19}$.

Outro elemento importante é que a noção de sagrado sacrílego, tal como interessava ao Collège, não estava restrita somente à vida coletiva, embora se manifestasse com mais frequência nela. Os domínios da sexualidade e do jogo, por exemplo, seriam tomados como espaços privilegiados de vivência do sagrado e estariam localizados justamente naquilo que Caillois chamou no trecho acima de "ponto de coincidência" entre o indivíduo e a sociedade. Leiris, em texto escrito para a publicação coletiva do grupo na Nouvelle Revue Française em 1938, explora as dimensões daquilo que considerou a experiência íntima do sagrado. Dada não apenas em rituais coletivos mas também na vida cotidiana, Leiris sugere que cada um pode ter a "sua" vivência do sagrado a partir da experimentação "dessa mistura de medo e de vínculo, essa atitude ambígua que determina a aproximação de uma coisa ao mesmo tempo atraente e perigosa" (Leiris 1995:103) ${ }^{20}$.

A noção de sagrado com a qual lidava o Collège, estava, definitivamente, mais ligada à uma dimensão metonímica que metafórica da atividade humana. Tratava-se de pensar a experiência sagrada como contagiosa, essa "força" da qual falava Bataille capaz de ser disseminada aos quatro ventos. Daí também parece vir a ideia, trazida no início desse texto, do Collége pensando a si mesmo como um "foco de energia”, encarregado de contagiar com esse sagrado revolucionário e ativo aqueles que por ali passassem. O modelo da magia, da forma como fora apresentado por Marcel Mauss e Henri Hubert (1904), também era, assim, uma referência para a "sociologia sagrada" do Collège. Como mostra o título do texto de Bataille publicado junto ao de Leiris na N.R.F. de 1938, L'apprenti sorcier, interessava aos membros do Collège serem "aprendizes de feiticeiros" (1938). Afinal, como mostram Mauss e Hubert em seu estudo clássico (1904), o mágico ou o feiticeiro é aquele que ao pensar, sonhar, recitar cantos e orações, ou apenas mover objetos, realiza transformações no mundo: "suas palavras, seus gestos, seu piscar de olhos, seus pensamentos mesmos são forças. Toda a sua pessoa transmite eflúvios, influências, aos quais se curvam a natureza, os homens, os espíritos e os deuses" (Mauss \& Hubert 2003: 70, grifos meus).

Tornar-se um aprendiz de feiticeiro seria, então, nos termos do Collège, aprender a movimentar o mundo com o pensamento, não separando, portanto, o saber da ação. O modelo da magia era justamente o modelo de ação política buscado pelo grupo em questão: o sagrado era não só objeto, mas também adjetivo da sociologia que pretendiam fazer. Ele se tornava, assim, uma perspectiva, uma maneira de olhar e ao mesmo tempo agir sobre o mundo circundante.

19 Podemos pensar a concepção do social em Durkheim usando uma metáfora orgânica, comum a seus trabalhos. A sociedade pode ser comparada a um coração, que precisa dos movimentos da sístole e da diástole (compressão e distensão) para seguir batendo, exercendo sua função. A sociedade é, em Durkheim, por excelência, a entidade mantenedora da ordem e os estados afetivos de desordem - anômicos - caracterizados por "movimentos exuberantes e violentos" são tidos como necessários para a revitalização e o equilíbrio da mesma ordem, que é sempre superior aos indivíduos que a compõem (Durkheim 1968: 572).

20 Sabe-se que paralelamente às atividades do Collège Bataille e Leiris se envolveram também na criação da Societé de psychologie collective, iniciativa de ambos com Adrien Borel, ex-psicanalista dos dois, e outros três psicanalistas (René Allendy, Paul Schiff e Pierre Janet), interessada em investigar as pontes entre a psicologia e as ciências sociais (Yvert 2004: 253). Bataille frequentou como paciente o consultório de Borel, membro fundador da Sociedade Psicanalítica de Paris (SSP), a partir de 1926 e Leiris, por indicação do primeiro, a partir de 1929 (Surya 1992; Armel 1997). 
Um último ponto merece ser ressaltado: se não havia dúvidas de que a noção de sagrado do Collège estava vinculada à uma crítica à modernidade ocidental, o mesmo não pode ser dito com relação à sua postura diante dos regimes nazifascistas que vinham se ampliando na Europa. Alvo de críticas por parte tanto de acadêmicos quanto de militantes, o grupo se mantinha em uma zona de ambiguidade com relação à interpretação de suas intenções políticas. Em carta a Caillois de junho de 1938, Marcel Mauss atentava, desde o ponto de vista da sociologia formal, para os perigos do irracionalismo contido nas iniciativas como a do Collège: "mesmo persuadido de que os poetas e os homens de grande eloquência podem às vezes ritmar uma vida social, sou cético quanto às capacidades de uma filosofia qualquer, e sobretudo uma filosofia de Paris, de ritmar o que quer que seja” (apud Caillois 1981: 205).

De outro lugar, Walter Benjamin, embora auditor das conferências do Collège e parceiro intelectual de alguns de seus membros, principalmente Bataille e Pierre Klossowski, chamava a atenção para o mesmo ponto: um certo "excesso metafísico e político do incomunicável”, que poderia "preparar o terreno psíquico favorável ao nazismo" (Klossowski apud Hollier, 1995: 884) ${ }^{21}$. A crítica advinha também de outros membros da Escola de Frankfurt, como Adorno e, ainda mais enfaticamente Horkheimer, que ao tomar contato com as propostas de Acéphale e do Collège, teria se expressado caracterizando-os em termos de uma "confusão irracionalista" (Weingrad 2001: 134).

As críticas ao Collège em termos de suas "conotações fascistizantes" parecem, assim, ter relação direta com o uso exacerbado da noção de sagrado denunciado por Leiris na carta a Bataille (Ginzburg 2011: 203). Se, como vimos, o apelo à experiência ambígua e convulsiva do sagrado era para o grupo uma maneira de se opor aos regimes nazifascistas - e sabemos que os intelectuais que formavam o Collège, principalmente Bataille, vinham de uma história de militância de esquerda e eram radicalmente contra o regime - ele era também, de um outro ponto de vista, similar a esses modelos políticos. $\mathrm{O}$ estudo dos símbolos, a importância do mito, o interesse pelas sociedades secretas e o recurso às experiências coletivas efervescentes eram características inegáveis dos autoritarismos recentes e ao mesmo tempo matérias de interesse do Collège. A crítica ao racionalismo por meio da noção de sagrado era perigosa nesse sentido, o de aproximar o Collège daquilo que ele visava combater. Mas como comenta precisamente Maurice Nadeau (1990), o grupo, longe de "empreender um fascismo à francesa", queria "lutar contra aquilo que lhe parecia uma regressão na ordem do pensamento empregando os mesmos meios" (1990: 20). Na tentativa de compreender e o combater o fascismo, a associação entendia que era preciso usar as mesmas armas do inimigo, reconhecendo o poder inegável do que podemos chamar aqui de uma política dos afetos.

Proponho, como breve exercício final, nos determos sobre aquele que foi o texto de origem do Collège de Sociologie. Escrito em 1937 por Caillois e apresentado a Bataille e Leiris em uma primeira reunião no café do Palais Royal, Vent d'hiver - que seria também publicado um ano depois em Pour un Collège de Sociologie, junto a Lapprenti sorcier de Bataille e Le sacré dans la vie quotidienne de Leiris

21 Walter Benjamin conhece o escritor, tradutor e membro do Collège de Sociologie Pierre Klossowski (1905-2001) em 1935. A partir daí estabeleceriam uma parceria intelectual, que renderia a Klossowski a tradução para o francês do ensaio "A obra de arte na era de sua reprodutibilidade técnica" de Benjamin (1936). Para mais detalhes sobre a relação entre eles e o trânsito entre França e Alemanha neste momento ver: Weingrad (2001). 
- traz em seu cerne aquelas que seriam as provocações teóricas mais interessantes (e também as mais criticáveis, como vimos) do Collège de Sociologie 22 .

\section{Vento de inverno}

Apesar de não conter nenhuma citação direta que indique a formação do Collège de Sociologie, o artigo de Caillois se mostra como uma espécie de manifesto de inauguração da associação, ilustrativo para a compreensão do empreendimento não apenas como um grupo de estudos stricto sensu, mas como um experimento. Isso porque nesse texto Caillois reflete sobre a importância da formação do que ele chama naquele momento de "comunidades morais", isto é, comunidades fundadas por afinidades eletivas entre seus membros. Para ele, tais grupos seriam como meios, no sentido orgânico da palavra, capazes de cultivar ideias contrárias àquelas vigentes na sociedade englobante ${ }^{23}$.

Em uma referência explícita ao trabalho de Marcel Mauss, Essai sur les variations saisonnières des sociétés eskimos (1906), o autor ressalta a importância e a urgência da constituição de comunidades morais para a ação política efetiva. Em alusão ao inverno dos esquimós, que na descrição de Mauss aparece como o tempo da reunião, da comunhão, das festas e da celebração do sagrado - em oposição ao verão, individualista e profano -, Caillois dirá que na sociedade contemporânea há também aqueles que se dispõem a enfrentar e a viver o inverno integralmente. Segundo o autor, "uma má estação, talvez uma Era quaternária - o avanço das geleiras - se abre para essa sociedade desmantelada, senil” e diante destas baixas temperaturas se encontram aqueles que "se reconhecem no ar rarefeito, que o inverno torna unidos, compactos, lado a lado, com consciência da sua força, os quais a nova primavera consagrará” (1995: 352-353).

Caillois parece querer chamar a atenção para a urgência do momento político vivido, a chegada do inverno coincidindo com a chegada do fascismo. De acordo com ele, aqueles que concebem uma sociedade "dessacralizada" não terão forças suficientes para combater o "avanço das geleiras", é preciso que os fortes se aglutinem em torno do sagrado. O inverno aparece, então, em uma dupla chave: como a imagem da catástrofe por vir e ao mesmo tempo metáfora de uma comunidade sagrada que seria capaz de revertê-la. Em suas palavras, se o vento de inverno se aproxima, é preciso encontrar aqueles que nestas baixas temperaturas se identificam, formando grupos capazes de gerar movimento em meio a uma "sociedade sem fervor" (idem:352).

O Collège seria, então, uma tentativa no sentido de gerar um "foco de energia" em meio ao quadro de urgência salientado metaforicamente por Caillois. Segundo o autor, esse tipo de grupo se assemelharia, pelo menos em termos de finalidade, a três outros tipos: às ordens monásticas, às formações

22 A publicação Pour un Collège de Sociologie é de julho de 1938 e se constitui como uma separata do número 298 da Nouvelle Revue Française. É formada por uma introdução escrita por Caillois, em que são reafirmados os propósitos do grupo, já salientados na declaração de 1937 publicada em Acéphale; bem como de três textos de seus fundadores: L'apprenti sorcier de Bataille, Le sacré dans la vie quotidienne de Leiris, ambos escritos para essa ocasião, e Vent d'hiver, de Caillois, escrito um ano antes quando da fundação do grupo. Hollier (1995) ressalta que na introdução a essa publicação Caillois enfatiza a ambição ativista do grupo, que na nota de 1937 estaria menos explícita.

23 Roger Caillois, consideravelmente mais jovem que Bataille e Leiris, tinha acabado de se formar em gramática na tradicional École Normale Supérieure quando entrou para o Collège de Sociologie. Embora com menos experiência intelectual que seus parceiros o "brilhante intelectual com ares de dândi" é quem toma inicialmente a dianteira do projeto (Felgine 1997: 7-8). 
paramilitares e às sociedades secretas primitivas. Isso porque nesses três casos seria possível ver uma separação clara de seus membros com relação ao resto da sociedade a qual pertencem; normalmente reduzidos à ilegalidade eles seriam tolerados a contragosto pelo poder oficial.

Espécies de transgressores do poder legítimo, os iniciados, ou colegiados, nesse caso, estabeleceriam para si e para seus comparsas uma moral própria e única. Moral que deveria, segundo Caillois, estar baseada em três virtudes: o "desprezo", o "poder" e a "cortesia" (idem: 349-351). Como um vírus em um corpo saudável a formação dessas pequenas comunidades deveria contaminar a sociedade que as circunda. Como vimos, trata-se aqui de pensar o sagrado enquanto uma força mágica, transmitida por contágio. Há também no texto de Caillois uma crítica ao utilitarismo, tema que veremos desenvolvido igualmente em trabalhos de Bataille da época, na medida em que o autor identifica o que chama de sociedade englobante com a sociedade utilitária.

As comunidades morais da qual fala seriam, então, o oposto: essencialmente improdutivas e "voltadas para o gozo", elas deveriam se inspirar nos rituais de desperdício das sociedades primitivas, os famosos potlatch descritos também por Mauss (1925) (idem: 345)24. Conectados por um movimento natural de atração e repulsão - que aproxima os iguais e repele os diferentes - esses pequenos grupos improdutivos seriam capazes de engendrar uma verdadeira epidemia revolucionária no coração de sua própria sociedade. Daí também a imagem ambígua do vento de inverno, que traz os maus agouros, mas que também é capaz de disseminar a semente do sagrado para outros territórios.

\section{Considerações finais: por uma política dos afetos}

$\mathrm{Na}$ apresentação à recente edição brasileira do livro $O$ que é o contemporâneo? e outros ensaios (2007), do filósofo italiano Giorgio Agamben, Susana Scramim e Vinícius Nicastro Honesko (2009) sugerem a preocupação do autor em pensar novas formas de lidar com a política. Os ensaios contidos no livro, que versam sobre a noção de amizade e sobre a noção de tempo, parecem querer apontar para uma dimensão pouco convencional dessa experiência. Se perguntam Scramim e Honesko:

Como pensar uma nova ação e uma nova política humanas para além das dimensões consensuais-democráticas que a filosofia e o pensamento político atuais parecem tomar como único e ultimo estágio evolucionário da humanidade? Ou, ainda, de modo liminar: como parar a máquina governamental em que parece ter se transformado toda a política, e ter acesso a uma nova política, uma política da amizade, calcada numa outra experiência do tempo e capaz de nos expor às exigências de compartilhamento da existência das quais não podemos nos esquivar?” (2009: 11).

É interessante perceber como a proposta do Collège de Sociologie, bem como a discussão sobre o sagrado feita em seu seio no fim dos anos 1930, pode ser cotejada lado à lado à questão colocada pelos autores acima. A ideia de pensar a política através do aparato conceitual da antropologia usado para a

24 Toda a obra de Bataille versa no sentido de uma crítica ao utilitarismo, mas é em 1933, em La notion de dépense, que pela primeira vez ele se debruçará sobre o tema, fazendo um elogio da noção de despesa inspirado diretamente pela leitura de L'essai sur le don (1925) de Mauss, ensaio em que o autor descreve os rituais melanésios, polinésios e esquimós de destruição de riquezas (Bataille 1975; Mauss 2003). 
compreensão das religiões primitivas oferece ao Collège justamente a possibilidade de pensar o campo do ativismo e da militância política de uma outra forma. No lugar de consenso, escolha, otimização e gestão, palavras tão comumente usadas no vocabulário político, o Collège escolhe energia, sagrado, contágio e comunidade. Mas o que significa efetivamente priorizar esses termos?

Criticado, como vimos, por romantizar o campo da política ou torná-lo por demais irracional, a experiência do Collège, se levada a sério, parece ser capaz de nos ensinar que o vocabulário antropológico dos estudos da religião, e, mais que ele, a própria experiência religiosa, pode ser aproveitada de maneira surpreendente pelos movimentos políticos. Trata-se, como também os ensaios contemporâneos de Agamben indicam, de pensar em como fazer uma política dos afetos, comprometida com a dimensão "nefasta" da experiência. Se a noção de sagrado lida justamente com dois aspectos primordiais da experiência humana, um ligado à lei, à forma, à razão e à estrutura e outro ligado ao desejo, ao informe, ao sentido e à desordem, o Collège nos convida a pensar não apenas sobre a relação ambígua entre esses polos, mas também sobre as potencialidades de exploração de um deles. O que ganhamos quando nos propomos pensar a ação política por meio da magia? Que relações guardam entre si o feiticeiro e o ativista? Em que sentido a festa e o ritual podem ser paradigma da luta? Seria o tempo do sagrado um tempo de revolução? Essas são perguntas que feitas nos anos 1930 pelo Collège ainda nos soam enigmáticas e contemporâneas.

Júlia Vilaça Goyatá é doutoranda em Antropologia Social na Universidade de São Paulo (USP).

\section{REFERÊNCIAS BIBLIOGRÁFICAS}

AMBrosinO, G.; BATAILlE, G., CAILLOIS, R., KLOSSOWSKI, P., LIBRA, P., MONNEROT, J. 1995 [1937]. “Déclaration sur la fondation d'un Collège de Sociologie”. In: HOLLIER, D. (org). Le Collège de Sociologie. Paris: Gallimard.

ARMEL, A. 1997. Michel Leiris. Paris: Fayard.

BATAILLE, G. et alii. 1991. Documents. Année 1929/1930. Edição fac-similar. Paris: Jean-Michel Place.

BATAILLE, G. 1970a [1935]. 'Contre-Attaque'. Union de lutte des intellectuels révolutionnaires. In: . Oeuvres complètes. Tome I. Premiers Écrits. Paris: Gallimard. .1970b [1936]. La conjuration sacrée. In: . Oeuvres complètes. Tome I. Premiers Écrits. Paris: Gallimard. .1975 [1933; 1949]. A parte maldita (precedida de A noção de despesa). Rio de Janeiro: Imago Editora. 
.1995a [1938]. La sociologie sacrée et les rapports entre 'societé', 'organisme' et 'être'. In: HOLLIER, D. (org). Le Collège de Sociologie. Paris: Gallimard.

.1995b [1938]. L'apprenti sorcier. In: HOLLIER, D. (org). Le Collège de Sociologie. Paris: Gallimard.

1997. Choix de lettres (1917-1962). Paris: Gallimard.

.2004 [1954].La publication d'Un cadavre. In : LEIRIS, M \& BATAILLE, G. Échanges et correspondences. Paris: Gallimard.

BATAILLE, G. ; CAILLOIS, R. ; LEIRIS, M. 1995a [1938]. Déclaration du Collège de Sociologie sur la crise internationale. In: HOLLIER, D. (org). Le Collège de Sociologie. Paris: Gallimard.

BATAILLE, G. ; CAILLOIS, R. ; LEIRIS, M. 1995b [1939]. Le Collège de Sociologie. In: HOLLIER, D. (org). Le Collège de Sociologie. Paris: Gallimard.

BRUMANA, F. G. 2005. O sonho dogon nas origens da etnologia francesa. São Paulo: Edusp.

CAILLOIS, R. 1974. Approches de l'imaginaire. Paris: Gallimard.

.1981a. Entretien donné à Hector Bianciotti et Jean-Paul Enthoven. In: CAILLOIS, R. et alii. Cahiers Pour en temps. Paris: Centre Georges Pompidou/Pandora Editions.

.1981b. Notes pour un itinéraire de Roger Caillois. In: CAILLOIS, R. et alii. Cabiers Pour en temps. Paris: Centre Georges Pompidou/Pandora Editions.

. 1995 [1938]. Vent d'hiver. In: HOLLIER, D. (org). Le Collège de Sociologie. Paris: Gallimard.

1950 [1939]. L’ homme et le sacré. Paris: Gallimard.

2008. Oeuvres, Paris: Gallimard.

CAILLOIS, R. \& OCAMPO, V. 1997. Correspondances. Paris: Éditions Stock.

DURKHEIM, E. 1968. Les formes élémentaires de la vie religieuse. Le système totémique em Australie. Paris: Presses Universitaires de France.

FELGINE, O. (org.). 1997. CAILLOIS, R. \& OCAMPO, V. Correspondances. Paris: Éditions Stock.

. "Vie et oeuvre.2008. In: CAILLOIS, R. Oeuvres. Paris: Gallimard.

FOURNIER. M. 1994. Marcel Mauss. Paris: Fayard.

.2007. Émile Durkheim (1858-1917). Paris: Fayard.

GINZBURG, C. 2011. Mitologia germânica e nazismo: sobre um velho livro de Georges Dumézil. 
In: . Mitos, Emblemas, Sinais: Morfologia e História. São Paulo: Companhia das Letras.

GOUARNÉ, I. 2013. L'introduction du Marxisme en France: philosoviétisme et sciences humaines (1929-1939). Rennes: Presses Universitaires de Rennes,

GOYATÁ, J. 2016. Georges Bataille e Michel Leiris: a experiência do sagrado. São Paulo: Humanitas. HEILBRON, J. 1985. “Les métamorphoses du durkheimisme, 1920-1940”, Revue française de sociologie, 26-2: 203-237.

HOLLIER, D. (org). 1995. Le Collège de Sociologie. Paris: Gallimard.

JAMIN, J. 1980. “Un sacré collège ou les apprentis sorciers de la sociologie”. Cahiers Internationaux de Sociologie, 68: 5-30.

LECOQ, D.\& LORY, J. 1987. Écrits d'ailleurs: Georges Bataille et les ethnologues. Paris: Éditions de la Maison des Sciences de l'Homme.

LEIRIS, M. \& CHAVASSE, P. 1968. Entretien avec Michel Leiris. Radio France-Culture, janeiro. Disponível em http://www.ina.fr/art-et-culture/litterature/audio/PHD99208104/michel-leiris-1. fr.html.

LEIRIS, M. 1992a. Journal 1922-1989. Paris : Gallimard.

LEIRIS, M. ; PRICE, S. ; JAMIN, J. 1992b. C'est-à-dire. Paris: Jean- Michel Place.

LEIRIS, M. 1994. L' homme sans honneur - notes sur le sacré dans la vie quotidienne. Editon établie, présentée et annotée par Jean Jamin, Paris: Jean Michel Place.

1995 [1938], Le sacré dans la vie quotidienne. In: HOLLIER, D. (org). Le Collège de Sociologie. Paris: Gallimard.

MAUSS, M. 1968. Oeuvres. Paris: Les Éditions de Minuit.

1981. Lettre a Roger Caillois. In: CAILLOIS, R. et alii. Cabiers Pour en temps. Paris: Centre Georges Pompidou/Pandora Editions.

2003. Sociologia e Antropologia. São Paulo: Cosac \& Naify.

MAUSS, M. \& HUBERT, H. 2005. Sobre o sacrifício. Ensaio sobre a natueza e a função do sacrifício. São Paulo: Cosac \& Naify.

MOTTA, A. 2006. A África Fantasma de Michel Leiris. In: CAVIGNAC, J.; GROSSI, M.; MOTTA, A. (orgs.). Antropologia Francesa no século XX. Recife: Editora Massangana.

NADEAU, M. 1985. História do surrealismo. São Paulo: Perspectiva.

NADEAU, M.; ARON, P.; VAN DER SCHUEREN, E. 1990. Entretien avec Maurice Na- 
deau. In: P. ARON \& E. VAN DER SCHUEREN (orgs.). Michel Leiris. Revue de l'Université de Bruxelles, 1990/1-2. Bruxelles: Editions de l'Université de Bruxelles.

PEIXOTO, F. 2006. O nativo e o narrativo: os trópicos de Lévi-Strauss e a África Fantasma de Michel Leiris. In: CAVIGNAC, J.; GROSSI, M.; MOTTA, A. (orgs.). Antropologia Francesa no século $X X$. Recife: Editora Massangana. .2007. A viagem como vocação: antropologia e literatura na obra de Michel Leiris. In: LEIRIS, M. A África Fantasma. São Paulo: Cosac \& Naify. . 2011. “O olho do etnógrafo", Sociologia \& Antropologia, v.01, n.02, pp. 195-215.

PROCHASSON, C. 1981. Le socialisme normalien (1907-1914). Université Paris 1, thèse sous la direction de M. Agulhon, 390 p.

RICHMAN, M. 1990. Anthropology and Modernism in France: From Durkheim to the Collège de Sociologie. In: MANGANARO, M. (org). Modernist Anthropology: from Fieldwork to Text. Princeton: Princeton University Press.

SCRAMIM, S. \& HONESKO, V. 2009. Apresentação. In: AGAMBEN, G. O que é o contemporâneo? e outros ensaios. Chapecó: Argos.

SOBRAL, L. F. 2008. "O pensamento selvagem de Michel Leiris”, Novos Estudos - CEBRAP, n.82: 207-215.

SURYA, M. 1992. La mort à l'oeuvre. Paris: Gallimard.

THIRION, A. 1981. La boussole d'obsidienne. In: CAILLOIS, R. et alii. Cahiers Pour en temps. Paris: Centre Georges Pompidou/Pandora Editions.

WEINGRAD, M. 2001. “The College of Sociology and the Institute of Social Research”, New German Critique, No. 84: 129-161.

YVERT, L (org.). 2004. In: LEIRIS, M. \& BATAILLE, G.. Échanges et correspondences. Paris: Gallimard.ZORZI, M. 2013. O "Dicionário" de Documents (1929-1930) e a antropologia de Georges Bataille. São Paulo: Dissertação de mestrado em Antropologia Social, USP. 

(1937-1939)

Resumo: O presente trabalho pretende explicitar o contexto de formação e as principais propostas de uma experiência efêmera, mas nem por isso menos significativa, ocorrida na França do entreguerras: o Collège de Sociologie. Fundado em 1937 para ser um grupo de estudos em torno de alguns temas de interesse comum entre seus organizadores - Georges Bataille (1897-1962), Michel Leiris (1901-1991) e Roger Caillois (1913-1987) - o grupo teve também o intuito de ser um lócus de ação política. A noção de sagrado, clássica na teoria antropológica francesa a partir de seu uso no trabalho de Émile Durkheim (1858-1917), Les formes eléméntaires de la vie religieuse (1912), ganha no Collège grande destaque: busca-se compreender essa ideia e, mais que isso, torná-la uma prática. Nesse sentido, há uma leitura renovada da noção mobilizada pela antropologia precedente: o sagrado é tanto objeto de estudo quanto perspectiva de análise que permite olhar para a sociedade contemporânea e, no limite, transformá-la.

Palavras-chave: Collège de Sociologie, antropologia, sagrado, política, religião.

\title{
A FOCUS OF ENERGY: THE COLLÈGE OF SOCIOLOGIE AND THE NOTION OF SACRED (1937-1939)
}

\begin{abstract}
This paper shows the context of composition and the main proposals of an ephemeral, but not less significant, experience in France between the wars: the College de Sociologie. Founded in 1937 to be a group of studies around some subjects of common interest among its organizers - Georges Bataille (1897-1962), Michel Leiris (1901-1991) and Roger Caillois (1913-1987) - the group was also a locus of political action. The concept of sacred, classic in french anthropological theory gains prominence in the College. Their attempt was to understand this idea and, more than that, make it a political practice. In this sense we can say that the experience of the College was a renewed reading of the notion enunciated by the preceding anthropology. For them the sacred was both an object of study and a point of view to see, criticize and change the contemporary European society.
\end{abstract}

Keywords: Collegge de Sociologie, anthropology, sacred, politics, religion.

RECEBIDO : 01/12/2017

APROVADO : $07 / 03 / 3018$ 
60 CAMPOS V.18(1-2), 2017 